\title{
Postsynaptic Shank Antagonizes Dendrite Branching Induced by the Leucine-Rich Repeat Protein Densin-180
}

\author{
Arne Quitsch, Kerstin Berhörster, Chong Wee Liew, Dietmar Richter, and Hans-Jürgen Kreienkamp \\ Institut für Zellbiochemie und klinische Neurobiologie, Universitätskrankenhaus Hamburg-Eppendorf, 20246 Hamburg, Germany
}

\begin{abstract}
Leucine-rich repeat and PDZ [postsynaptic density-95 (PSD-95)/Discs large/zona occludens-1] domain proteins such as scribble and Densin-180 have been implicated in the establishment of cell-cell contacts. Here, we show that Densin-180, which has been identified as a constituent of the postsynaptic density in excitatory synapses interacts with the postsynaptic scaffold protein shank (shank1-3). The interaction involves a two-point attachment of the C-terminal region of Densin-180 with the Src homology 3 domain and the N-terminal part of the proline-rich region of shank proteins. The N-terminal leucine-rich repeat region, which is not involved in binding shank, targets Densin-180 to the plasma membrane in transfected cells and to the basolateral membrane of epithelial cells. Nevertheless, coexpression of shank leads to a redirection of Densin-180 into intracellular clusters. In cultured hippocampal neurons, Densin-180 overexpression induces excessive branching of neuronal dendrites, which occurs at the expense of clusters for the postsynaptic marker PSD-95. Coexpression of shank3 abrogates branch formation and targets Densin-180 into postsynaptic clusters instead. Shank blocks binding of $\delta$-catenin but not $\alpha$ CaM kinase II to Densin-180; because $\delta$-catenin has been shown to induce branching and neurite formation, our data suggest a mechanism where shank could block the activation of a Densin-180-dependent signaling pathway by $\delta$-catenin.
\end{abstract}

Key words: leucine-rich repeats; ProSAP; PDZ domain; LAP proteins; proline-rich region; dendrite branching

\section{Introduction}

Leucine-rich repeat (LRR) and PDZ [postsynaptic density-95 (PSD-95)/Discs large/zona occludens-1 (ZO-1)] domain containing (LAP) proteins constitute a family of proteins, which are characterized by an N-terminal set of 16 LRRs and a variable number of C-terminal PDZ domains. Four mammalian LAP genes, hScrib, Lano, erbin, and Densin-180, have been described previously (for review, see Bryant and Huwe, 2000). Evidence from the invertebrate homologs of these proteins, scribble in Drosophila and let-413 in Caenorhabditis elegans, suggests that LAP proteins are involved in the proper positioning of cell-cell junctions (Bilder and Perrimon, 2000; Legouis et al., 2000). In epithelial cells, LAP proteins are targeted to the basolateral membrane via their LRRs (Legouis et al., 2003); however, LAP expression also dictates the protein composition of the apical membrane (Bilder and Perrimon, 2000). Densin-180, a neuron-specific LAP, was identified as a constituent of the postsynaptic density in excitatory synapses (Apperson et al., 1996). Densin-180 was suggested to be a transmembrane (TM) protein with a single membranespanning hydrophobic segment, thus positioning the N-terminal region in the extracellular space (Apperson et al., 1996). How-

Received July 7, 2004; revised 0ct. 27, 2004; accepted Nov. 17, 2004.

Support from the Deutsche Forschungsgemeinschaft (SFB545/B7 to D.R. and H.-J.K.) and the European Commission (QLG3-CT-1999-00908 to D.R.) is gratefully acknowledged. This report was presented by A.Q. as part of a PhD thesis at the University of Hamburg. We thank Hans-Hinrich Hönck and Agata Blaszczyk-Wewer for excellent technical assistance, Tobias Böckers (University of Ulm, Ulm, Germany) for shank3/ProSAP2 constructs, and Kenneth Kosik for the $\delta$-catenin/EGFP construct.

Correspondence should be addressed to Hans-Jürgen Kreienkamp, Institut für Zellbiochemie und klinische Neurobiologie Universitätskrankenhaus Hamburg-Eppendorf, Martinistrasse 52, 20246 Hamburg, Germany. E-mail: Kreienkamp@uke.uni-hamburg.de.

D0I:10.1523/JNEUROSCI.2699-04.2005

Copyright $\odot 2005$ Society for Neuroscience $\quad$ 0270-6474/05/250479-09\$15.00/0 ever, this was recently questioned because of the lack of accessibility of the N-terminal part to extracellular reagents (Izawa et al., 2002). Similar to the other LAP proteins, interacting proteins have been clearly identified thus far only for the C-terminal region of Densin-180. Thus, the armadillo repeat-containing protein $\delta$-catenin binds to Densin-180 (and erbin) via a type-I PDZ domain-binding motif (DSWV-Stop) in the C terminus of $\delta$-catenin (Izawa et al., 2002). Similar motifs in the cateninrelated proteins p0071 and ARVCF (armadillo repeat gene deleted in velo-cardio-facial syndrome) (Laura et al., 2002; JaulinBastard et al., 2002) are involved in the interaction of these proteins with erbin in epithelial cells. In addition, the ErbB2 receptor binds the erbin PDZ domain via a more distantly related motif (DVPV-Stop), which is required for the basolateral targeting of the receptor (Borg et al., 2000) (but see Dillon et al., 2002).

Densin-180 itself is also involved in interactions with other postsynaptic proteins; Walikonis et al. (2001) as well as Strack et al. (2000) demonstrated that by binding $\alpha$-actinin (via the PDZ domain) and the $\alpha$-subunit of $\mathrm{Ca}^{2+} /$ calmodulin-dependent kinase II (CaMKII $\alpha$; via a segment more proximal to the putative TM domain), Densin-180 can induce a ternary complex of the three proteins. Thus, LAP proteins appear to play a dual role, first in the proper positioning of cell-cell junctions and the determination of polarity and second in the assembly of signaling complexes such as the NMDA receptor-associated complex in the postsynaptic density.

We describe here a further interaction of Densin-180 within the postsynaptic density by identifying Densin-180 as a binding partner for the shank family of postsynaptic proteins. Shank proteins are believed to play a role in the functional and morphological maturation of dendritic spines (Sala et al., 2001). Our data indicate that in the absence of shank, Densin-180 promotes enhanced branching of neuronal dendrites through its N-terminal 
LRRs. Coexpressed shank can counteract this pathway and recruit Densin-180 to postsynaptic sites instead.

\section{Materials and Methods}

Yeast two-hybrid screen. The cDNA coding for the Src homology 3 (SH3) domain of human somatostatin receptor interacting protein (SSTRIP)/ Shank1 (amino acids 444-646) (Zitzer et al., 1999) was amplified by PCR and subcloned into the pAS2 vector (Clontech, Heidelberg, Germany). This bait plasmid was cotransformed together with a pretransformed human brain Matchmaker cDNA library in pACT-2 (Clontech) into the CG1945 yeast strain. Clones growing in the absence of Leu, Trp, and His were picked and their phenotype confirmed by $\beta$-galactosidase assay and retransformation. Plasmids from positive candidates were isolated and sequenced.

For additional analysis, cDNA fragments coding for different C-terminal regions of Densin-180 were amplified by PCR and cloned into the pACT2 vector. Protein-protein interaction was tested by retransformation of these constructs together with the SSTRIP/Shank1 SH3 domain into yeast and assaying the ability to grow in the absence of Leu, Trp, and His.

Fusion proteins and antibodies. For the generation of glutathione $S$-transferase (GST)-fusion proteins of SSTRIP/Shank1, Shank2, and Shank3, corresponding cDNA fragments were cloned into pGEX4T-2 (AP Biotech, Freiburg, Germany); for $\mathrm{His}_{6}$-tag fusions, cDNA fragments of Densin-180 were cloned into pQE-30 (Qiagen, Hilden, Germany). Expression and purification using glutathione Sepharose (AP Biotech) or Ni-nitrilo-tetraacetic acid-agarose (Qiagen) were performed as described by the manufacturers. Anti-shank antibodies were used as described previously (Zitzer et al., 1999; Soltau et al., 2002); anti-Densin180 antiserum was generated using a GST-fusion protein of Densin-180 (aa 1242-1537; custom antiserum generation by Biogenes, Berlin, Germany). Although this antigen contains the PDZ domain of Densin-180, which is highly similar to erbin, the antiserum does not cross-react with endogenous erbin in human embryonic kidney (HEK) cells, as detected by Western blotting. Monoclonal anti-PSD-95 was obtained from Upstate Biotechnology (Lake Placid, NY). Anti-FLAG and anti-myc were from Sigma (St. Louis, MO), and anti-T7 was from Novagen (Madison, WI). Rabbit anti-ZO-1 was obtained from Zymed (San Francisco, CA).

Expression constructs. For expression in eukaryotic cells, SSTRIP/ Shank1 (aa 72-2182) was cloned into the plasmid enhanced green fluorescent protein (pEGFP)-C1 vector (Clontech). In addition, a construct containing residues 1-1288 in pcDNA3 (Invitrogen, Leek, The Netherlands) was used (Zitzer et al., 1999). Full-length constructs of Shank2 (aa 1-1259; obtained from J. T. Parsons, University of Virginia, Charlottesville, VA) and Shank3 (aa 1-1740; obtained from T. Böckers, University of Ulm, Ulm, Germany) and several deletion constructs of SSTRIP/ Shank1 and Shank2 were used in the vector pCDNA3.1A (Invitrogen), which fused a C-terminal Myc epitope to the proteins. For the mapping experiments in HEK293 cells, Densin-180 deletion constructs were constructed in the vector p3xFlag-Myc-CMV26 (Sigma) in frame with the $\mathrm{N}$-terminal Flag epitopes. CamKII $\alpha$ and P21-activated protein kinase interacting exchange factor $\beta$ ( $\beta$ Pix) full-length constructs were amplified by PCR from brain cDNAs and cloned into the vector pCDNA-T7 (Roth et al., 1997). For the transfection of primary neurons, full-length Densin-180 (aa 1-1542) was amplified from a rat brain cDNA library and cloned in the vectors pCDNA3.1A (Invitrogen) and pEGFP-C1 (Clontech).

Precipitation assays. Synthetic peptides corresponding to the $\mathrm{C}$ termini of guanylate kinase domain-associated protein (GKAP)/synapse-associated protein-associated protein (SAPAP) (sequence IYIPEAQTRL) and $\delta$-catenin (HYPASPDSWV) were obtained from Genemed Synthesis (San Francisco, CA). The peptides were coupled to $N$-hydroxyl-succinimidyl (NHS)-activated Sepharose (Amersham Biosciences, Piscataway, NJ) at a concentration of $3 \mathrm{mg} / \mathrm{ml}$ Sepharose matrix.

Transfected HEK cells were lysed in $1 \mathrm{ml}$ of radioimmunoprecipitation assay (RIPA)-lysis buffer (50 mu Tris-HCl, pH 8.0, $150 \mathrm{~mm} \mathrm{NaCl,} \mathrm{1 \%} \mathrm{NP-}$ 40, 0.5\% Na-deoxycholate, 5 mm EDTA, 0.1\% SDS, 0.2 mm phenylmethylsulfonyl fluoride, $1 \mu \mathrm{g} / \mathrm{ml}$ pepstatin, $10 \mu \mathrm{g} / \mathrm{ml}$ leupeptin) per culture dish on ice for $15 \mathrm{~min}$. Lysates were centrifuged $(10 \mathrm{~min} ; 20,000 \times g)$ to remove insoluble matter. For precipitation of shank protein, cleared HEK cell lysates were incubated with GKAP peptide Sepharose for $2 \mathrm{~h}$ at $4^{\circ} \mathrm{C}$. For immuno- precipitation of T7-tagged $\beta$-Pix, $20 \mu \mathrm{l}$ of T7-antibody Sepharose (Novagen) was added to the supernatant fraction and incubated for $1 \mathrm{~h}$ at $4^{\circ} \mathrm{C}$. After washing, all precipitated complexes were boiled in SDS sample buffer and analyzed on SDS-PAGE followed by Western blotting.

For immunoprecipitation from rat brain, forebrains from adult rats were homogenized in deoxycholic acid-lysis buffer $(50 \mathrm{~mm}$ Tris- $\mathrm{HCl}, \mathrm{pH}$ 9.0, $1 \% \mathrm{Na}$-deoxycholate, $50 \mathrm{~mm}$ Na-fluorid, $20 \mu \mathrm{M} \mathrm{ZnCl}, 1 \mathrm{~mm} \mathrm{Na}-$ orthovanadate, $0.2 \mathrm{~mm}$ phenylmethylsulfonyl fluoride, $1 \mu \mathrm{g} / \mathrm{ml}$ pepstatin, $10 \mu \mathrm{g} / \mathrm{ml}$ leupeptin) for $1 \mathrm{~h}$ at $4^{\circ} \mathrm{C}$ and cleared by centrifugation ( 40 min; $20,000 \times g$ ). Shank was precipitated by incubating the lysate for $2 \mathrm{~h}$ at $4^{\circ} \mathrm{C}$ with $100 \mu \mathrm{l}$ of GKAP peptide Sepharose. To precipitate Densin$180,5 \mu \mathrm{l}$ of purified anti-Densin- 180 antibody was added to the lysate and after incubation for $1 \mathrm{~h}$ at $4^{\circ} \mathrm{C}$, the immune complex was precipitated by the addition of $20 \mu \mathrm{l}$ of protein A/G-agarose (Santa Cruz Biotechnology, Santa Cruz, CA). The matrices were washed five times with RIPA buffer and eluted by boiling in SDS sample buffer. After separation by SDS-gel electrophoresis, the samples were subjected to Western blotting.

Pulldown assays. Glutathione $S$-transferase fusion proteins of Shank1 (aa 504-665) and Shank3 (aa 393-553) SH3 domains, the Shank1 PDZ domain (aa 665-797), and the Shank2 proline-rich region (aa 311-667) were expressed and purified. Proteins were not eluted but left on the glutathione-Sepharose. To avoid nonspecific interaction, the Sepharose was blocked with TBS ( $150 \mathrm{~mm} \mathrm{NaCl}, 50 \mathrm{~mm}$ Tris-HCl, $\mathrm{pH}$ 7.9) containing $2 \% \mathrm{BSA}$ and $2 \mathrm{~mm}$ DTT. Thirty micrograms of $\mathrm{His}_{6}$-Densin-180 fusion protein (aa 1242-1537) were added in TBS with $1 \mathrm{mg} / \mathrm{ml} \mathrm{BSA}$ and $2 \mathrm{~mm}$ DTT and incubated for $2 \mathrm{~h}$ at $4^{\circ} \mathrm{C}$. After extensive washing with TBS containing $1 \%$ Tween 20 , bound fusion proteins were eluted by boiling in SDS sample buffer. After separation by SDS-gel electrophoresis, the samples were subjected to Western blotting.

Cell culture and transfection. HEK293 cells were cultivated and transfected as described previously (Roth et al., 1997). Madin-Darby canine kidney-II (MDCK-II) cells (obtained from Kai Simons, Max-Planck-Institut, Dresden, Germany) were transfected and selected for stable expression using the G418 resistance of pcDNA3.1 vectors. Hippocampal neurons were prepared at embryonic day 19 and plated at a density of $\sim 500 \mathrm{cells} / \mathrm{mm}^{2}$ on poly-L-lysine-coated glass coverslips. Cultures were grown in neurobasal medium (Invitrogen) supplemented with B27 (Invitrogen) and $0.5 \mathrm{~mm}$ glutamine. Glutamate $(12.5 \mu \mathrm{M})$ was included for the first $4 \mathrm{~d}$ in culture. Transfections were performed using the calcium phosphate method as described by Blichenberg et al. (1999) at $7 \mathrm{~d}$ after plating.

Immunocytochemistry. Transfected HEK or MDCK-II cells growing on glass coverslips were fixed with $4 \%$ paraformaldehyde in PBS and permeabilized with $0.1 \%$ Triton X-100 in PBS for 2 min at room temperature ( $15 \mathrm{~min}$ in the case of MDCK-II). After blocking ( $2 \%$ horse serum in PBS) for $1 \mathrm{~h}$ at room temperature, cells were incubated with anti-T7 or anti-myc antibodies (diluted 1:5000 in blocking solution), rabbit ZO-1 (1:750), or purified polyclonal anti-Densin-180/anti-Shank antibodies (diluted 1:500 in blocking solution) for $2 \mathrm{~h}$ at room temperature, followed by $1 \mathrm{~h}$ of incubation with cyanin 3 (Cy3)- (red), Alexa488-, or Cy2-(green) conjugated secondary antibodies (diluted 1:500 in PBS). Immunostaining was visualized by confocal microscopy using a Zeiss (Thornwood, NY) LSM 410 microscope as described previously (Roth et al., 1997). Vertical sections were reconstructed using the LSM software (Zeiss). Images were further processed using Adobe Photoshop version 4.0 (Adobe Systems, San Jose, CA).

Hippocampal neurons in culture were processed for immunofluorescence staining as described by Soltau et al. (2004) after 9 or $14 \mathrm{~d}$ in culture. For overexpressed proteins, antibodies were used at a dilution of $1: 2000$ at $4^{\circ} \mathrm{C}$ overnight. For staining of endogenous proteins, affinitypurified rabbit anti-Densin-180 (1:10) and guinea pig anti-shank (1:20) antibodies were incubated for $4 \mathrm{~h}$ at room temperature, followed by $1 \mathrm{~h}$ of incubation with $\mathrm{Cy} 2$ and $\mathrm{Cy} 3$ conjugates as described above. Immunostaining was visualized by fluorescence microscopy using an Aristoplan microscope (Leitz, Wetzlar, Germany).

For the analysis of branching and total dendritic branch tip number, all images were taken with Openlab 2.2.5 software (Improvision, Lexington, MA). A $40 \times$ oil immersion Neofluor objective was used, and the cell body was placed in the center of the field $(175 \times 175 \mu \mathrm{m})$. Cells were only selected when they were isolated from other transfected cells. Branch points 
A

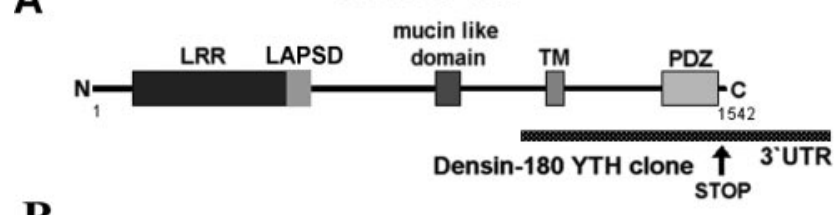

B

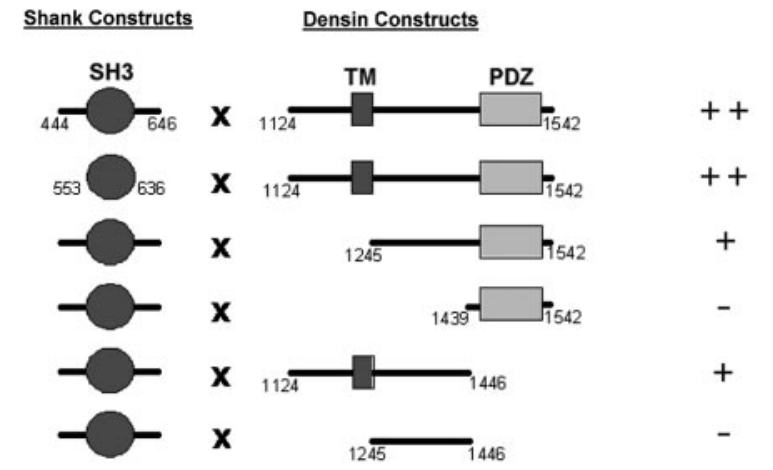

C
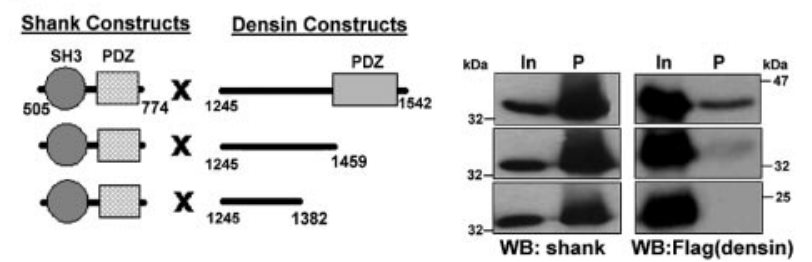

Figure 1. Interaction of the SH3 domain of shank1 with Densin-180. A, Domain structure of Densin-180. The position of the yeast two-hybrid (YTH) clone obtained with the shank1 SH3 domain is indicated. LAPSD, LAP-specific domain; UTR, untranslated region. $B$, Mapping of the interaction in the yeast two-hybrid system. Shank and Densin-180 constructs in pAS-2 and pACT2 were cotransformed into yeast strain CG-1945; protein interaction, as detected by growth on His-deficient media, was scored as,,+++ or - . C, Mapping of the interaction in transfected HEK cells. A shank1 construct containing the SH3 and PDZ domains was transfected into HEK cells together with N-terminal Flag epitope-tagged Densin-180 constructs as indicated. From cell lysates in RIPA buffer, shank was precipitated using GKAP peptide Sepharose. Precipitates (P) were analyzed by Western blotting using anti-shank PDZ and anti-Flag (Densin180) antibodies. In, Input.

or end tips were assigned using digitized images in Adobe Photoshop version 4.0. Only protrusions longer than $4 \mu \mathrm{m}$ were considered as branches. Constructs were tested in four independent experiments. Statistical significance of the data was determined using two-tailed Student's $t$ tests.

\section{Results}

By yeast two-hybrid screening, we searched for interaction partners of the SH3 domain of shank1; of 1 million clones screened, one clone consistently and specifically interacted with the shank1 bait; sequencing showed that this clone contains the $3^{\prime}$ part of the Densin-180 cDNA (Apperson et al., 1996) corresponding to residues $1125-1542$ of the Densin-180 protein (Fig. 1A). Densin180 consists of $\mathrm{N}$-terminal LRR and cysteine-rich domains, followed by a mucin-like domain, a putative transmembrane segment, and a C-terminal PDZ domain. Of these, only the TM segment and the PDZ domain were included in the clone fished out from the yeast two-hybrid assay (Fig. 1A). A closer view at this part of the sequence does not reveal any particular proline-rich segment that can be identified as a candidate motif mediating the interaction with the shank SH3 domain. Additional mapping in the yeast system showed that although both the PDZ and the TM domains are neither strictly required nor sufficient for the interaction with the shank $\mathrm{SH} 3$ domain, the strength of the interaction is reduced after deleting either domain, such that a construct lacking both the PDZ and TM part no longer binds to the $\mathrm{SH} 3$ domain (Fig. $1 B$ ).

For additional analysis of the interaction, we expressed FLAGtagged Densin-180 constructs in HEK293 cells together with a shank1 construct containing the $\mathrm{SH} 3$ and the PDZ domain of shank1. Shank was then precipitated from cell lysates by immobilized GKAP-C-terminal peptide, which interacts strongly with the PDZ domain of shank proteins (Naisbitt et al., 1999). Here, we observed again that the strength of the interaction was gradually lost when the Densin-180 fragment was deleted stepwise from the C-terminal end (Fig. 1C).

Interaction of Densin-180 with full-length shank proteins was also tested in this system. Coexpression of shank 3 or shank 1 and precipitation of shank by GKAP Sepharose led to specific coprecipitation of the Densin-180 fragment (Fig. 2A). We could not precipitate Densin-180 when it was expressed in the absence of any shank protein. Furthermore, we could not detect interaction of Densin-180 with $\beta$ PIX; $\beta$ PIX contains an SH3 domain, which is most similar to that of shank1. However, this SH3 domain was apparently not able to interact with Densin-180, further demonstrating the specificity of the interaction between shank and Densin-180. As a further negative control, we chose shank2/ cortactin-binding protein 1 (Du et al., 1998; Böckers et al., 1999), because a splice variant without the $\mathrm{SH} 3$ domain was available to us as an expression clone. Much to our surprise however, coexpression of this clone with Densin-180 and precipitation of shank2 via the GKAP/PDZ interaction consistently led to coprecipitation of Densin-180 (Fig. 2 A). In addition, a shank3 deletion construct lacking the $\mathrm{SH} 3$ domain was also able to coprecipitate with Densin-180 (data not shown). This suggested that Densin180 might interact with shank proteins via a second point of attachment. The leucine-rich region of Densin-180 (Densin1470 ) or the entire N-terminal part (Densin1-1114; lacking the sequence obtained as a target in the yeast two-hybrid screen) did not coprecipitate with shank3, whereas full-length Densin-180 was efficiently coprecipitated, indicating that regions of Densin180 other than the $\mathrm{C}$ terminus are not involved in binding shank. We explored the possibility of a second point of interaction by expressing several truncated shank 2 constructs with the Densin$180 \mathrm{C}$ terminus. Interaction between both proteins, as detected by coprecipitation, was lost when the $\mathrm{N}$-terminal part of the long proline-rich domain, between residues 318 and 451, was deleted from the shank construct (Fig. $2 B$ ). Within Densin-180, the region in the $\mathrm{C}$ terminus immediately preceding the $\mathrm{PDZ}$ domain appeared to be essential for the interaction.

Because the interaction in HEK cells, as shown here, could also be mediated by a third, unknown protein present in these cells, we also performed GST pulldown assays with isolated fusion proteins of shank and Densin-180 to show that the second interaction is also a result from direct binding between both proteins (Fig. 2C). The Densin-180 fragment was expressed as a $\mathrm{His}_{6}$-tag fusion protein, whereas various shank fragments were expressed as GST fusions. After purification, GST-fusions were left attached to the glutathione Sepharose, incubated with $\mathrm{His}_{6}$-Densin-180, and, after washing, eluted with SDS sample buffer. $\mathrm{His}_{6}$-Densin-180 could be detected in the eluate from GST fusions of the SH3 domains of shank1 and shank3 and also from the proline-rich segment (residues 311-667) of shank2. $\mathrm{His}_{6}$-Densin-180 did not bind to the PDZ domain of shank1 or GST alone (Fig. 2C).

HEK cells expressing Densin-180, shank, or both were evaluated by immunocytochemistry using a confocal microscope; 
shank1 immunoreactivity was distributed rather diffuse in the cytosol of transfected cells, sometimes associated with filaments as described by Romorini et al. (2004) in COS cells. Shank3 was found in large intracellular clusters. Densin-180, when transfected alone, was detected in or at the plasma membrane (Fig. 3). In sections taken at the bottom of cells, close to the substrate, Densin-180 could also be detected in protrusions emanating from the cell body (data not shown). When shank1 was coexpressed with Densin-180, the distribution of both proteins changed such that they appeared in many intracellular clusters; both proteins were colocalized in these clusters, as apparent by yellow staining in Figure 3. In these experiments, Densin-180 was no longer localized at the plasma membrane. Similarly, shank3 coexpression removed Densin-180 from the plasma membrane and led to relocalization into those large intracellular clusters where shank3 resides also in the absence of Densin-180. Shank2 also led to the removal of Densin-180 from the plasma membrane, leading to intracellular colocalization. When shank3 was coexpressed with a Densin-180 construct containing only the $\mathrm{N}$-terminal leucine-rich repeat region (Densin-LRR), shank3 is again found in the intracellular clusters seen before, but the Densin-fragment is localized at the plasma membrane (see below for an analysis of regions of Densin-180 required for membrane targeting). Coexpression of Densin-180 with $\beta$ PIX did not remove Densin-180 from the plasma membrane.

We also analyzed the effect of a second interaction partner of the C-terminal region of Densin-180, namely $\delta$-catenin, on the intracellular distribution of Densin-180. In contrast to shank proteins, $\delta$-catenin is colocalized with Densin-180 at the plasma membrane of coexpressing cells. Even in cells exhibiting large amounts of intracellular $\delta$-catenin, coexpressed Densin-180 is not redistributed into the interior of the cell (one example is shown in Fig. 3).

To confirm that the interaction between shank and Densin180 occurs in vivo, we performed coprecipitation experiments from adult rat brain and colocalization in cultured hippocampal neurons. Densin-180 was precipitated with a rabbit anti-Densin180 antiserum from solubilized rat brain membranes. In the input of this reaction as well as in the Densin-180 precipitate, shank was detected in the form of several bands of molecular weights of $180 \mathrm{kDa}$ and higher by Western blotting with a guinea pig antishank antiserum. These were not detected when precipitation was performed with a nonrelated control serum (Fig. 4A). Shank itself was precipitated from membranes solubilized in $1 \%$ deoxycholate using GKAP Sepharose, and Densin-180 was detected in the precipitate using the Densin-180 antiserum. The specificity of this precipitation was ascertained by performing the precipitation reaction with the peptide KASTLSHL (derived from the rat somatostatin receptor 3) coupled to Sepharose. This peptide carries at its $\mathrm{C}$ terminus a type-I PDZ domain recognition motif
B

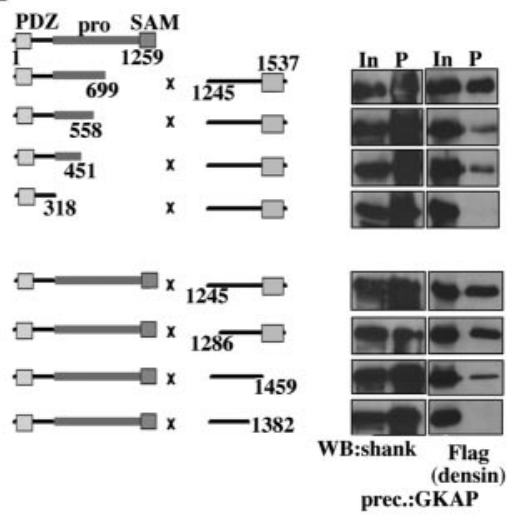

C

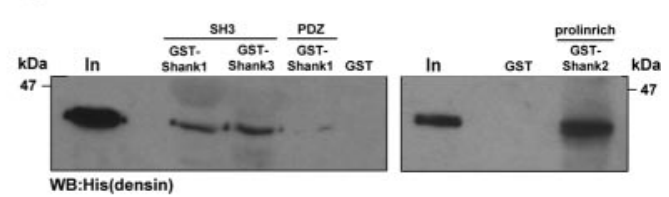

Figure 2. Densin-180 binds to shank proteins via a second point of interaction in the proline-rich region of shank. $A$, Densin-180 (top 5 panels), EGFP (panel 6), or myc-tags (bottom 2 panels) were coexpressed with shank cDNA PDZ and anti-Flag antibodies, respectively. C, His -tagged Densin-180 (residues 1242-1537) was incubated with glutathione beads carrying GST fusions of various parts of shank proteins, as indicated. After washing, bound proteins were eluted with SDS sample buffer and analyzed by Western blotting using a $\mathrm{His}_{6}$-tag antibody. In, Input.

similar to that of GKAP but does not bind to shank and does not coprecipitate Densin-180 (Fig. 4A). Together, these experiments demonstrate that Densin-180 exists in a complex with shank proteins in the rodent brain in vivo.

In cultured hippocampal neurons, both shank and Densin180 were detected in a punctate pattern by immunohistochemistry, consistent with the postsynaptic localization that has been described previously for both proteins (Apperson et al., 1996; Böckers et al., 1999; Naisbitt et al., 1999). Merging the two pictures derived from the red (shank) and green (Densin-180) channels revealed extensive colocalization of both proteins, evident as yellow staining (Fig. 4B).

Shank has been shown to be involved in the morphological and functional maturation of dendritic spines (Sala et al., 2001), whereas no information is available on the role of Densin-180 in synapse formation or in the regulation of neuronal morphology. When expressed in cultured hippocampal neurons, EGFP-tagged Densin-180 induced the formation of an elaborate network of processes, which could be clearly differentiated from the morphology of control neurons expressing EGFP alone (Fig. 5a). Densin-180 itself is localized to this network. Induction of branching by Densin-180 is clearly visible when neurons are analyzed $2 \mathrm{~d}$ after transfection (Fig. $5 b, 7+2$ ); however, the apparent intensity of branching and process formation increases strongly when cells were left in culture for an additional $5 \mathrm{~d}$ (Fig. 

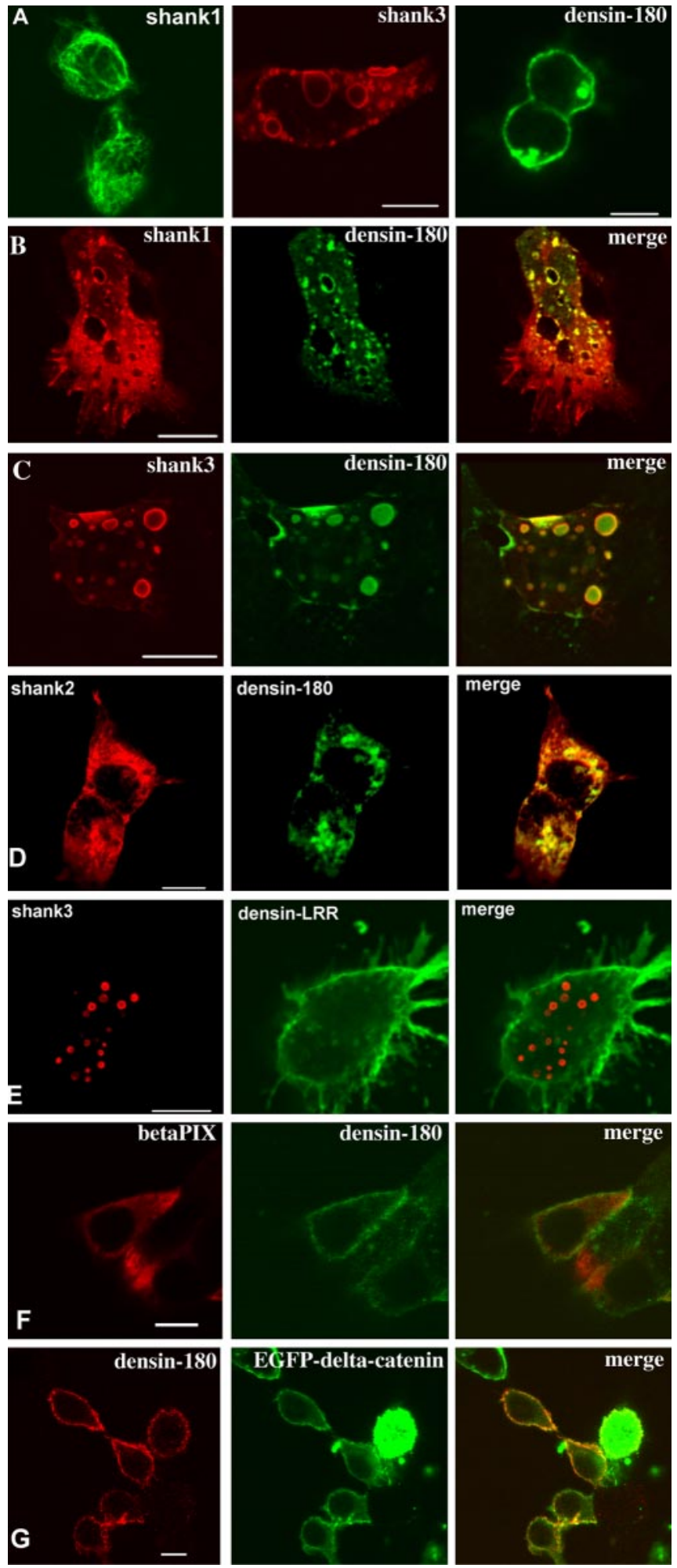

Figure 3. Shank targets Densin- 180 into intracellular clusters. Expression vectors for EGFPshank1 $(A)$, Shank1-3 without tag $(B-G), \beta P I X$, EGFP- $\delta$-catenin, and Densin-180 were transfected into $H E K$ cells either alone $(A)$ or in combination $(B-G)$. Shank was visualized by staining using EGFP autofluorescence $(A)$ or with rbAnti-shank, followed by Cy3-labeled anti-rabbit antibodies (red fluorescence). Densin-180 was visualized by monoclonal mouse anti-myc antibody, followed by Cy2-labeled anti-mouse antibodies ( $A-C$, green fluorescence), by rbAntiDensin-180, followed by Cy2-labeled anti-rabbit ( $D$, red fluorescence), or by mouse anti-myc, followed by $C y 3$-labeled anti-mouse ( $E$, red fluorescence). $\beta$ PIX was labeled by anti-T7, followed by Cy3-labeled anti-mouse ( $D$, red fluorescence), and $\delta$-catenin was visualized by the EGFP-autofluorescence $(E)$. All pictures are confocal sections taken approximately at the level of the center of the cells. Scale bars, $5 \mu \mathrm{m}$.
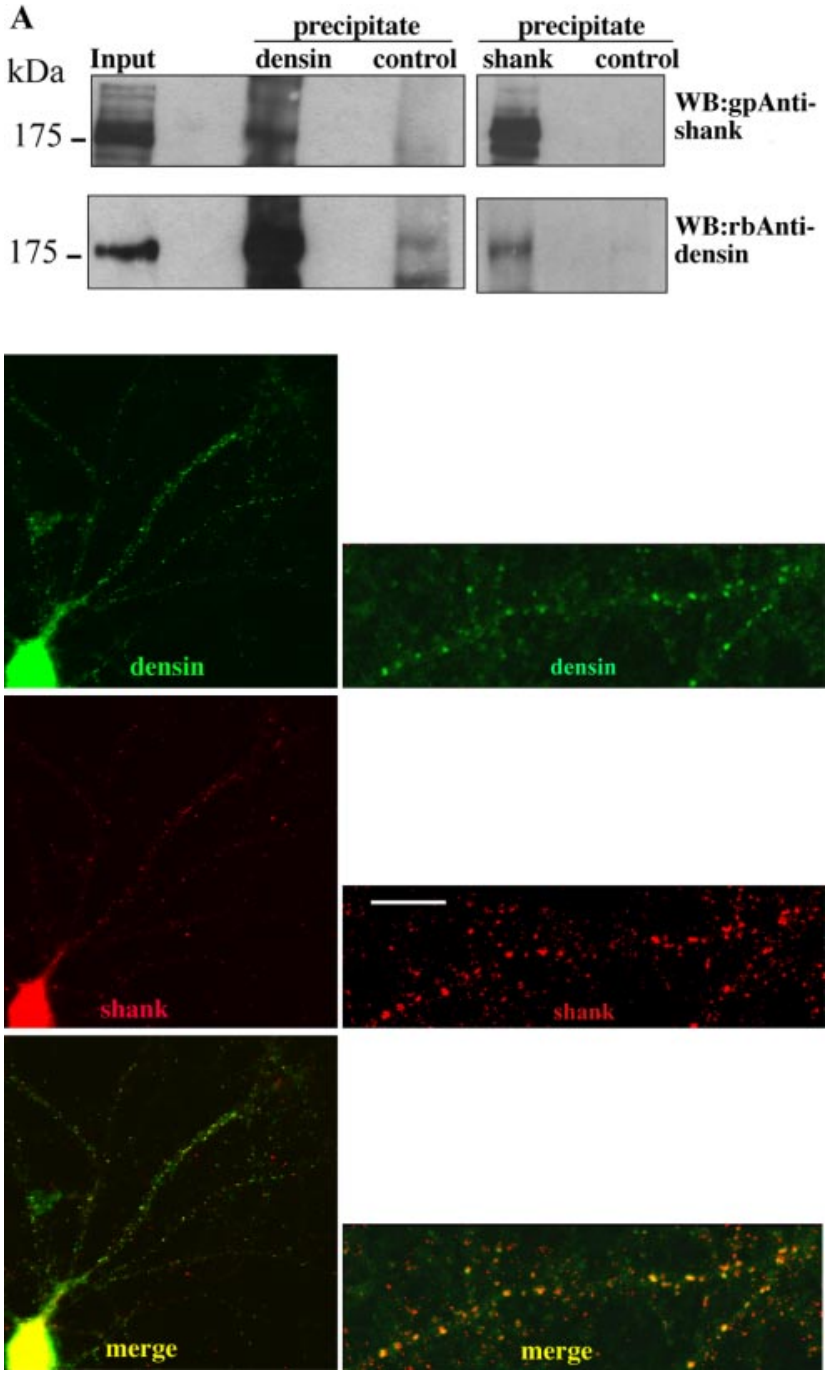

Figure 4. Shank and Densin-180 interact in vivo. A, Coprecipitation. Rat brain tissue was solubilized in deoxycholate buffer and cleared by centrifugation (Input). The lysate was subjected to immunoprecipitation, using rbAnti-Densin-180 or control antisera (left panels), or to peptide affinity purification, using GKAP C-terminal peptide, or a control peptide immobilized on NHS Sepharose (right panels). All samples were analyzed by Western blotting using shankspecific and Densin-180-specific antisera, as indicated. B, Colocalization. Hippocampal neurons were kept in culture for $17 \mathrm{~d}$; after fixation with methanol, neurons were stained with affinitypurified gpAnti-shank, followed by Cy3-labeled anti-guinea pig secondary antibodies (middle panel) and affinity-purified rbAnti-Densin-180, followed by Alexa488-labeled anti-rabbit (top panel). Shown are overviews (left) and enlargements (right). Overlay of both fluorescence signals demonstrates extensive colocalization of both proteins in a punctate pattern (yellow staining; bottom panel). Scale bar, $5 \mu \mathrm{m}$.

$5 a, b, 7+7)$. Most of these increased arborizations originate from the main dendrites of transfected cells, as identified by costaining for the dendritic marker MAP2. MAP2 staining is strong on the main dendrite but hardly detectable in the arborizations induced by Densin- 180 .

We tried to establish which of the different domains of Densin-180 is responsible for regulating neuronal morphology. Several deletion constructs were generated and expressed in hippocampal neurons as well as in HEK cells and in the polarized epithelial cell line MDCK-II. In neurons, only constructs that did contain the N-terminal leucine-rich repeat region were able to elicit a branching response similar to that seen with full-length Densin-180 (Fig. 5c). Constructs containing only the C-terminal part that was involved in the interaction with shank did not pro- 
A

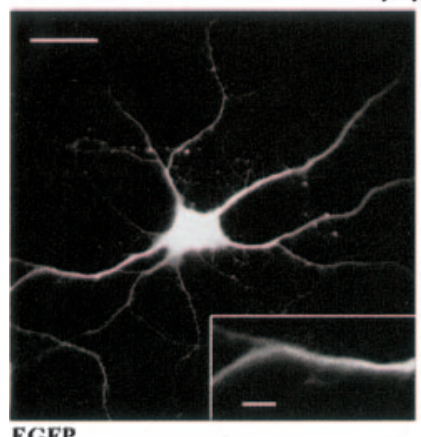

EGFP
$7+7$

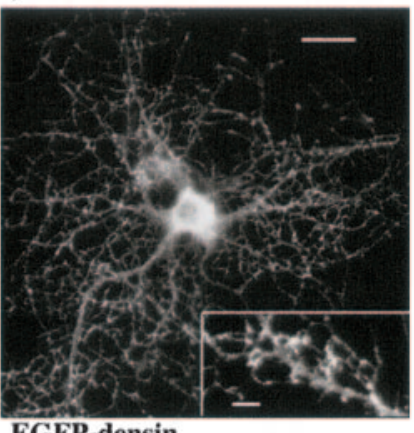

EGFP-densin
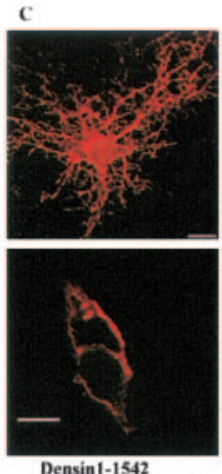

Densin 1-1542
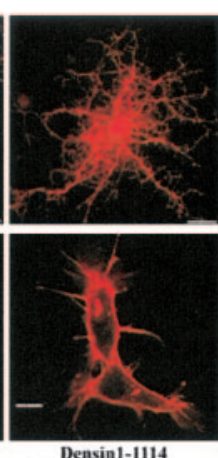

Densin1-1114
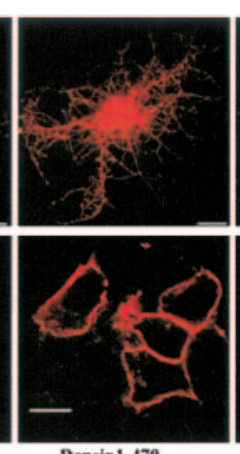

Densin $1-470$
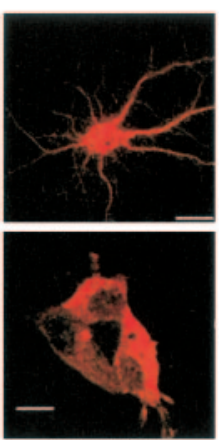

Densin455-1542
B
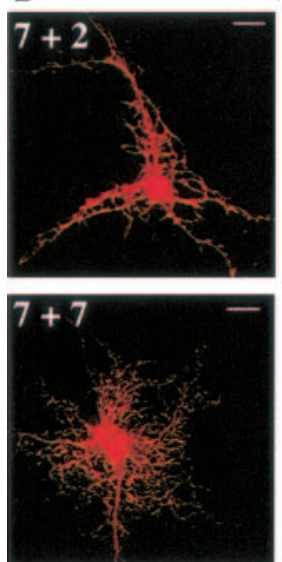

Myc - Cy3
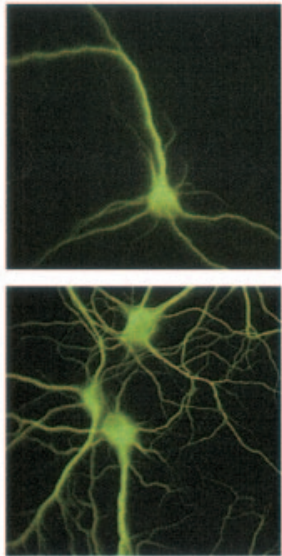

MAP2 - Cy2
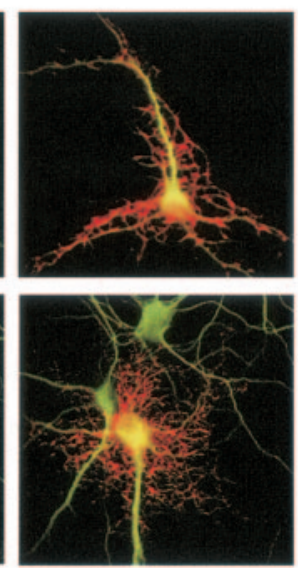

merge
D
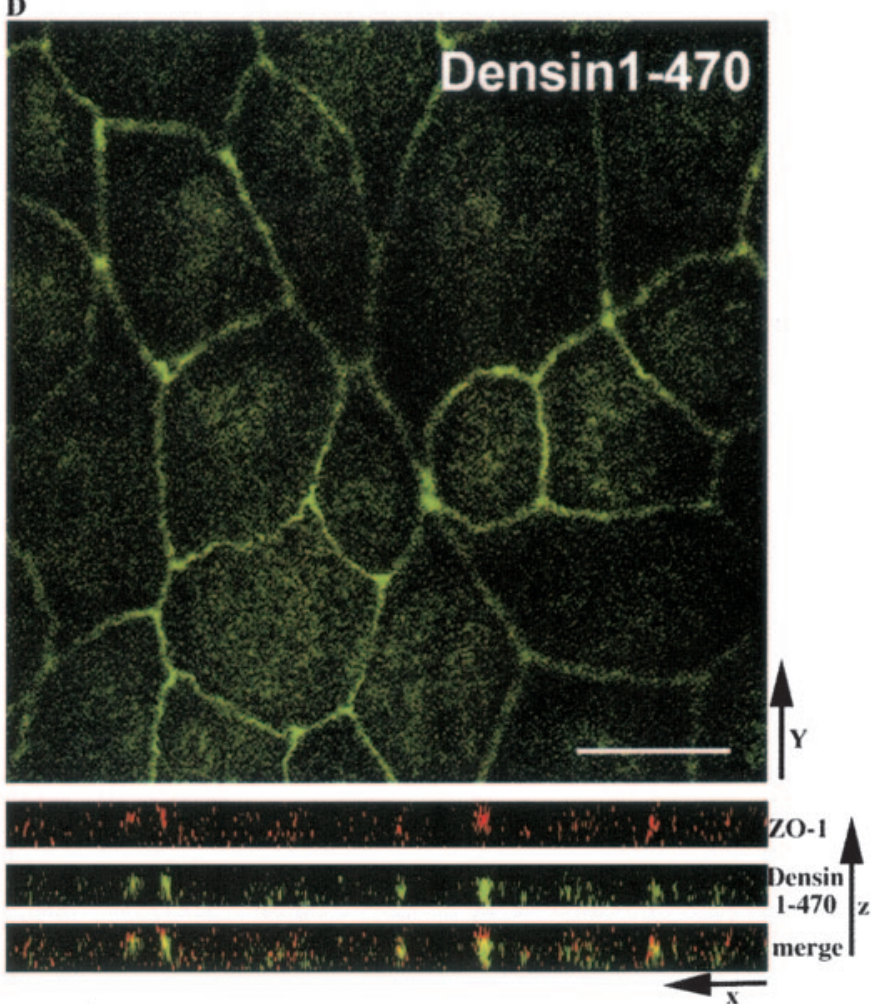

Figure 5. Densin-180 induces branching of neuronal dendrites. A, Hippocampal neurons were kept for $7 \mathrm{~d}$ in culture. After transfection with vectors coding for EGFP or EGFP-Densin-180, cells were cultivated for another $7 \mathrm{~d}(7+7)$ and stained for EGFP. B, Costaining for MAP2. Neurons were transfected after $7 \mathrm{~d}$ in culture with the Densin-180-myc construct; after $2 \mathrm{~d}(7+2)$ or $7 \mathrm{~d}(7+7)$ in culture, cells were fixed, and overexpressed Densin- 180 was detected by anti-myc, followed by Cy3-anti-mouse. MAP2 was detected using a polyclonal MAP antiserum (kindly provided by Dr. Stefan Kindler, Institut für Zellbiochemie, Hamburg, Germany), followed by Cy2-anti rabbit. C, Mapping of functional domains of Densin-180. Neurons were transfected with various deletion constructs of Densin-180, as indicated (top panel) and stained for the presence of Densin-180 using the ant-myc antibody as before. In parallel, constructs were transfected into HEK293 and assayed for their ability to target the protein to the plasma membrane. Note that only constructs that contain the leucine-rich repeat region are localized at the plasma membrane in HEK293 cells and have the ability to induce branching of dendrites in transfected neurons. Scale bars: neurons, full view, $20 \mu \mathrm{m}$; dendrite enlargements, HEK cells, $5 \mu \mathrm{m}$. D, MDCK-II cells stably expressing the Densin- 180 LRR region (Densin1-470) were stained for Densin (green) and the tight junction marker Z0-1 (red; vertical sections only). Horizontal $x y$ sections (left) were recorded on the confocal microscope; vertical $x z$ sections (right) were then reconstructed using LSM software. Note the delineation of green (Densin) fluorescence by the red (Z0-1) signal. Scale bar, $5 \mu \mathrm{m}$; thickness of $x z$ sections, $7 \mu \mathrm{m}$.

duce this kind of response. In HEK cells, constructs containing the LRRs were localized to the plasma membrane, whereas constructs lacking this region were distributed diffusely throughout the cellular cytoplasm (Fig. 5c). Thus, we observed a clear correlation of the ability of Densin-180 to induce branching and to localize to the plasma membrane of transfected cells. Because the LRR region of the Densin- 180 homologs erbin and scribble has been shown to mediate basolateral targeting in epithelia, we analyzed whether the LRR region of Densin-180 can perform the same function. Indeed, when stably transfected into the polarized epithelial cell line MDCK-II, LRR Densin-180 was sorted to the basolateral membrane (Fig. $5 d$, green fluorescence). The upper limit of the basolateral membrane was clearly delineated by costaining for the tight junction marker ZO-1 (red fluorescence in vertical sections).

Additional analysis of dendrites from Densin-180-expressing neurons indicated that the increased branching induced by Densin-180 occurs at the expense of the formation of postsynaptic specializations. Dendritic clusters of PSD-95 were strongly reduced by Densin-180 expression as depicted in Figure $6 a$. However, presynaptic clusters for synaptophysin were found to decorate the dendrites of Densin-180 overexpressing cells similar to control cells (data not shown). The effects of Densin-180 overexpression, however, could be reversed by coexpression of shank. 
A
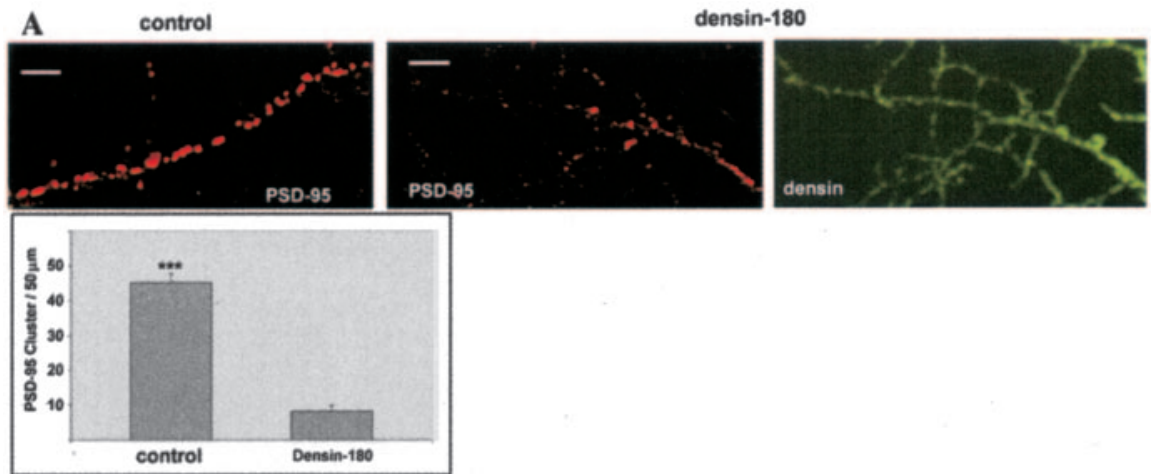

B

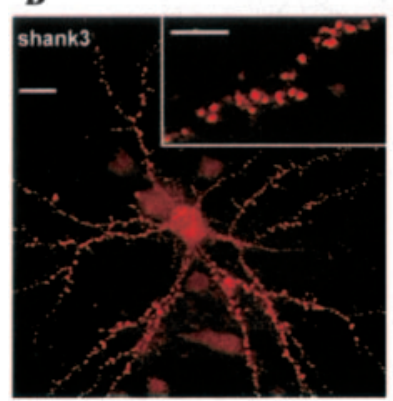

Densin-180 + shank 3
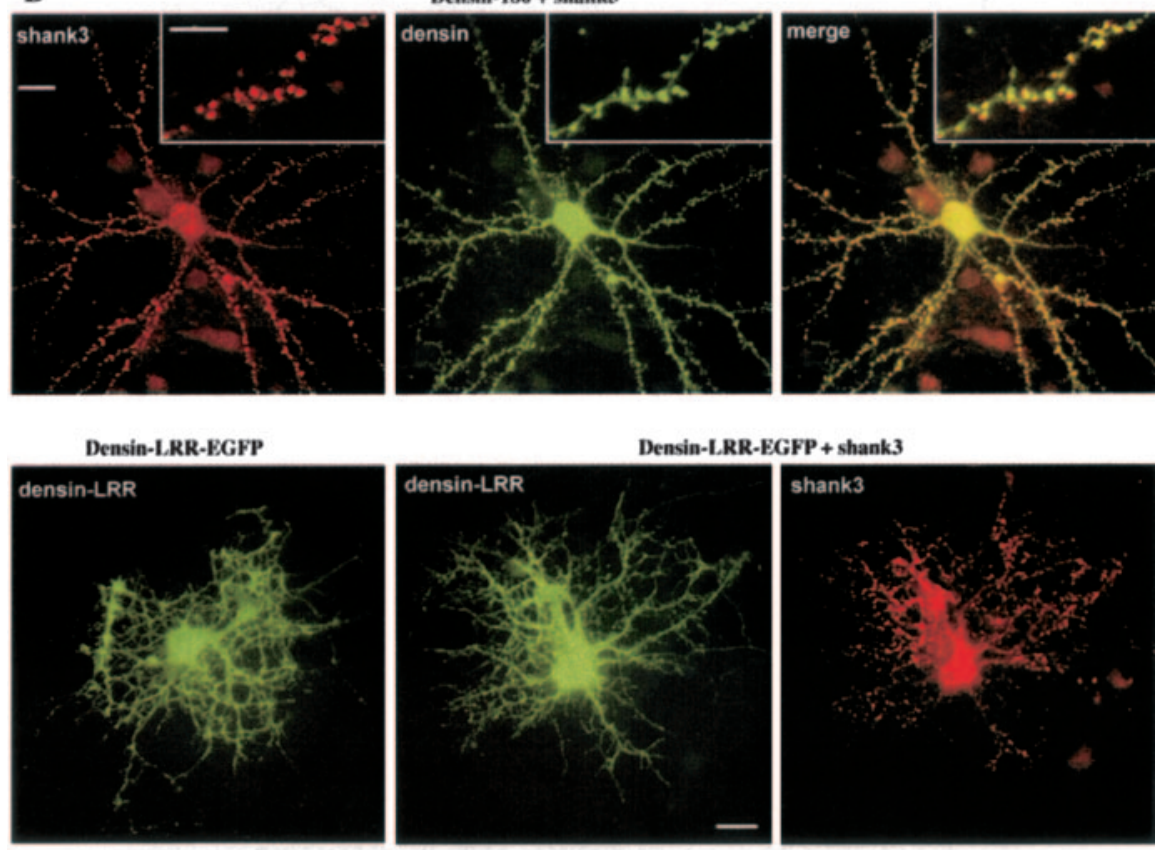

GFP + shank
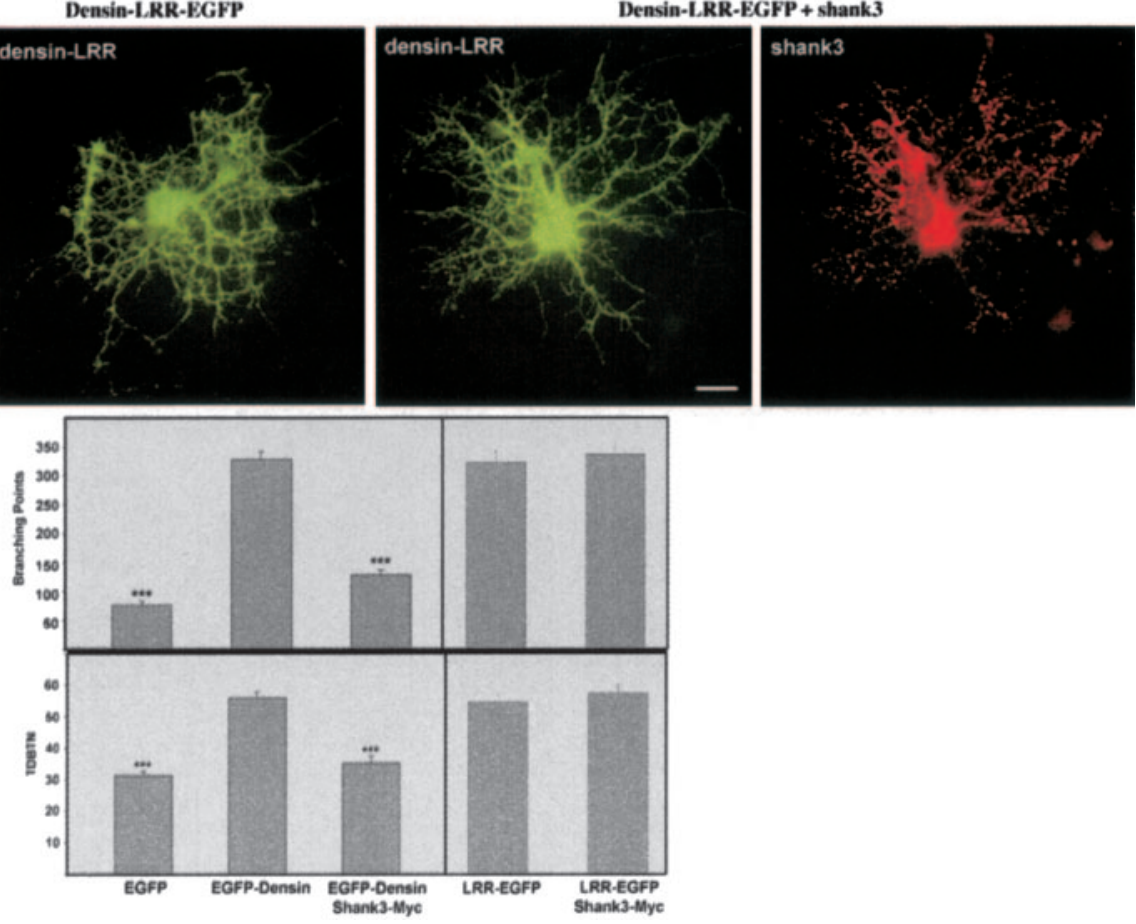

Figure 6. Relation of dendrite branching to the formation of postsynaptic complexes. $A$, Dendrites of control neurons (left) or neurons overexpressing Densin-180 (middle, right) were stained for the postsynaptic marker protein PSD-95 (left, middle) or the overexpressed Densin-180 (right). The number of PSD-95 puncta per $50 \mu \mathrm{m}$ sections of individual dendrites was evaluated; *** significantly different from Densin-180-expressing cells, $p<0.0001$, as determined by two-tailed Student's $t$ tests. Scale bar, 5 $\mu \mathrm{m} . B$, After $7 \mathrm{~d}$ in culture, neurons were cotransfected with constructs coding for EGFP-Densin-180 and myc-tagged Shank3/ ProSAP2 (top panel), the leucine-rich region of Densin-180 (Densin-LRR) alone (second panel, left), or in combination with shank3 (second panel, middle and right). After 7 additional days, neurons were fixed and stained for Shank3 and EGFP-Densin-180. Note the extensive, punctate colocalization of both proteins in the merged picture for full-length Densin-180 (and Shank3). Transfected cells from this figure and Figure $5 A$ were evaluated for their TDBTN and the number of branch points ( $>35$ neurons for each experimental condition; ${ }^{* * *}$ significantly different from Densin-180-expressing cells; $p<0.0001$ ), as determined by two-tailed Student's $t$ tests. Scale bar, $20 \mu \mathrm{m}$; inset, $5 \mu \mathrm{m}$.
When Densin-180 is cotransfected with shank3, shank is localized in many clusters on the dendrite, which, in keeping with previously published results, correspond to postsynaptic accumulations of shank protein. In the presence of shank, Densin180 is also targeted into these clusters, as evident by abundant colocalization of both proteins seen in Figure 6b. Shank apparently prevents Densin-180 from forming the highly branched dendritic network, which was seen before in the absence of coexpressed shank (Fig. 6) This was evident as a reduction in the total number of dendritic branch tips (TDBTN), which was strongly increased by Densin-180 expression and reduced by coexpression of shank3. Another parameter that we tested was the number of dendritic branch points, which was increased more than threefold by Densin-180 expression and reduced almost to control level by shank3 coexpression (Fig. 6b). When branching was induced by expression of a construct containing the leucinerich repeats of Densin-180 lacking the C-terminal region, which interacts with shank, branching is not blocked by coexpression of shank. This demonstrates that the interplay between shank and Densin180 in the regulation of dendritic morphology requires the interaction between both proteins (Fig. 6b).

Additional work was devoted to the question of how shank could interfere with Densin-180-associated signaling pathways. Several interacting partners of the $\mathrm{C}$ terminus of Densin-180 have been described previously: Strack et al. (2000) as well as Walikonis et al. (2001) reported binding of CaM kinase II to a region $\mathrm{C}$ terminal to the putative transmembrane domain. $\delta$-Catenin, which binds the PDZ domain of Densin-180, has recently been shown to induce a highly branched phenotype in hippocampal neurons in culture, similar to that observed here with Densin180-overexpressing neurons (Martinez et al., 2003). We examined both proteins for their ability to interact with shank3/ Densin-180 in a triple complex by coexpression in HEK cells and precipitation of shank using GKAP Sepharose as above. In these experiments, the CaM kinase $\alpha$-subunit could be precipitated with shank when Densin-180 was present, suggesting that indeed a triple complex shank-Densin-180-CaM kinase could be formed. Much to our surprise, $\delta$-catenin could be precipitated by shank in the absence of Densin-180 coexpression (Fig. $7 a, b)$. One possibility might be that shank interacts with endogenous erbin in HEK 
cells, which also interacts with and might indirectly precipitate $\delta$-catenin. We think that this is unlikely, because the region preceding the PDZ domain differs strongly between erbin and Densin-180. In the presence of Densin-180, however, the amount of $\delta$-catenin coprecipitating with shank was strongly reduced, demonstrating that $\delta$-catenin is excluded from the shank/Densin-180 complex. To further substantiate this observation, we analyzed the Densin-180-catenin interaction more directly by precipitating Densin-180 from cell extracts using an immobilized peptide corresponding to the $\mathrm{C}$-terminal sequence of $\delta$-catenin, which includes the DSWV-Stop motif involved in the interaction with the Densin-180 PDZ domain. Densin-180 expressed in HEK cells could be coprecipitated by this method in the absence, but not in the presence, of shank. These data clearly show that by binding to the C terminus of Densin-180, shank makes the PDZ domain inaccessible to the binding of the $\delta$-catenin PDZ ligand (Fig. 7c).

\section{Discussion}

We have described here an interaction between two prominent constituents of the postsynaptic density, Densin-180 and shank. By our analysis in yeast and HEK cells as well as in vitro using purified components, it becomes clear that all three shank family members may interact with the C-terminal region of Densin-180. The interaction is not limited to a single point of contact, as has been frequently described for PDZ type interactions, which usually affect the very $\mathrm{C}$ terminus of $\mathrm{PDZ}$ ligands. Instead, both the $\mathrm{SH} 3$ domain of shank ( $\mathrm{N}$ terminal to its PDZ domain) and part of the proline-rich region (C-terminal to its PDZ domain) are involved. Similarly, within Densin-180, larger parts of the C-terminal region are involved, as deletions from both the $\mathrm{N}$-terminal and the C-terminal end gradually affect binding of Densin-180 to shank.

Shank proteins are multidomain proteins that are localized at the interface between membrane receptors and the actin cytoskeleton within the postsynaptic density (for review, see Böckers et al., 2002). Through various direct and indirect interactions, shank proteins can link different types of neurotransmitter receptors into a larger complex; therefore, shank proteins have been classified as master scaffolds within the PSD (Sheng and Kim, 2000). Because shank mRNAs are present in dendrites, local synthesis of shank might play a role in the local assembly of the postsynaptic protein complex (Böckers et al., 2004). Consistent with a central role within this complex, overexpression of shank1 in cultivated hippocampal neurons promotes the accumulation of postsynaptic proteins at the synapse and a morphological and functional maturation of dendritic spines (Sala et al., 2001).

Overexpression of Densin-180, as shown here, leads to a quite different effect: Densin-180 does not increase the number or intensity of postsynaptic clusters (e.g., for PSD-95) but eliminates those clusters. So far, our experiments cannot differentiate whether the overall level of PSD-95 protein in dendrites is decreased or the clusters are dispersed into a more diffuse labeling pattern, because we cannot rule out that diffuse labeling for

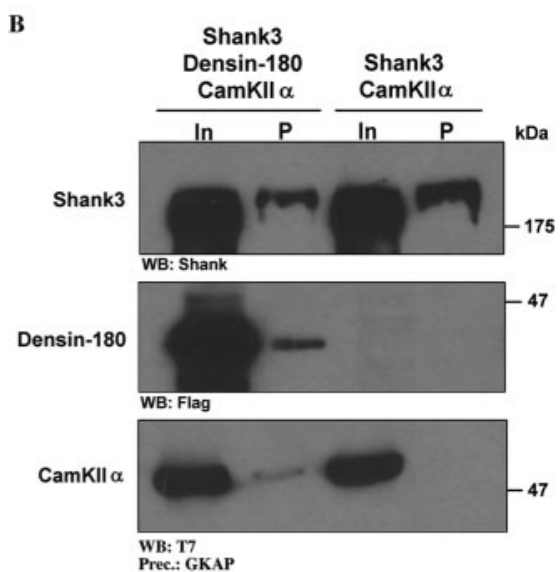

-95 might fall below our detection limit. On a morphologica level, Densin leads to aberrant branching of neurites; this aberrant branching is apparently incompatible with the formation of dendritic spines and postsynaptic specializations. It is also apparent that the overexpressed full-length Densin-180 is not incorporated into postsynaptic clusters.

The morphological effects of Densin-180 do not require the C-terminal parts of the molecule but are mediated by the $\mathrm{N}$-terminal stretch of leucine-rich repeats. These repeats are also required for the association of Densin-180 with the plasma membrane. Apperson et al. (1996) originally proposed that Densin180 is a transmembrane protein, with the N-terminal part comprising the LRRs located in the extracellular space. This is in contrast to other LAP family members that do not contain any signal peptide, which would allow for export of the N-terminal part of the molecule (Saito et al., 2001). The transmembrane orientation of Densin-180 was recently questioned by Izawa et al. (2002), who observed that the protein is not accessible to biotinylating agents applied from the extracellular side. We performed similar experiments that support the intracellular localization of Densin-180 (data not shown). In addition, our observation that the leucine-rich region is sufficient for the targeting of the protein to the plasma membrane (Fig. 5) indicates that Densin-180 is membrane anchored by this part of the molecule and not by the putative transmembrane region. Our observation that the LRRs of Densin-180 are sufficient for targeting to the basolateral membrane in polarized epithelial cells further supports the notion that the LRRs of Densin-180, scribble, and erbin are equivalent in their function and localization with respect to the plasma membrane. Thus, the experimental data available to date prefer a model that puts Densin-180 in line with the other members of the LAP family; in these, the LRRs are located intracellularly and are responsible for subcellular targeting of the protein (e.g., to the basolateral membrane in epithelial cells) (Legouis et al., 2003).

A similar "branching" phenotype, as observed here, was found 
by Martinez et al. (2003) as well as Kim et al. (2002) when overexpressing $\delta$-catenin in pheochromocytoma PC12 cells or in primary hippocampal neurons. $\delta$-Catenin interacts via its C-terminal PDZ ligand motif with the PDZ domains of Densin180 as well as erbin (Izawa et al., 2002; Laura et al., 2002). Thus, we reasoned that $\delta$-catenin and Densin-180 might be involved in a common signaling pathway that leads to the branched morphology of neurons. So far, our data are consistent with a model where shank, by interacting with Densin-180 and therefore blocking the accessibility of its PDZ domain for $\delta$-catenin, could interfere with this branching phenotype. Consequently, shank cannot block the branching phenotype of the isolated LRR domain of Densin-180, because this truncated molecule does not contain an interaction site for shank.

Competition among Shank, D-catenin, and Densin-180 is likely to occur in vivo at synapses, because all three proteins are enriched in the PSD fraction (Apperson et al., 1996; Naisbitt et al., 1999; Jones et al., 2002).

Shank coexpression interferes with the targeting of full-length Densin-180 to the plasma membrane in HEK cells and with the ability of Densin-180 to induce abnormal branching in cultivated neurons. Because shank binds to the C-terminal part of Densin180 (and not the LRR region), we propose that shank changes the overall conformation of Densin-180 such that the N-terminal part may no longer target the protein to the membrane. In neurons, the interaction with shank also appears, in addition, required to recruit Densin-180 to the postsynaptic density. Additional work will be directed at identifying possible interaction partners of the LRR region of Densin-180. Huang et al. (2003) have shown recently that the LRRs of erbin interfere with activation of the MAP kinase pathway by ras; a similar interference with small G-protein signaling might be an attractive model to explain the effects of Densin-180 in dendrite branching.

\section{References}

Apperson ML, Moon IS, Kennedy MB (1996) Characterization of Densin180 , a new brain-specific synaptic protein of the $O$-sialoglycoprotein family. J Neurosci 16:6839-6852.

Bilder D, Perrimon N (2000) Localization of apical epithelial determinants by the basolateral PDZ protein Scribble. Nature 403:676-680.

Bilder D, Schober M, Perrimon N (2003) Integrated activity of PDZ protein complexes regulates epithelial polarity. Nat Cell Biol 5:53-58.

Blichenberg A, Schwanke B, Rehbein M, Garner CC, Richter D, Kindler S (1999) Identification of a cis-acting dendritic targeting element in MAP2 mRNAs. J Neurosci 19:8818-8829.

Böckers TM, Kreutz MR, Winter C, Zuschratter W, Smalla KH, SanmartiVila L, Wex H, Langnaese K, Bockmann J, Garner CC, Gundelfinger ED (1999) Proline-rich synapse-associated protein-1/cortactin binding protein 1 (ProSAP1/CortBP1) is a PDZ-domain protein highly enriched in the postsynaptic density. J Neurosci 19:6506-6518.

Böckers TM, Bockmann J, Kreutz MR, Gundelfinger ED (2002) ProSAP/ Shank proteins-a family of higher order organizing molecules of the postsynaptic density with an emerging role in human neurological disease. J Neurochem 81:903-910.

Böckers TM, Segger-Junius M, Iglauer P, Bockmann J, Gundelfinger ED, Kreutz MR, Richter D, Kindler S, Kreienkamp HJ (2004) Differential expression and dendritic transcript localization of Shank family members: identification of a dendritic targeting element in the $3^{\prime}$ untranslated region of Shank1 mRNA. Mol Cell Neurosci 26:182-190.

Borg JP, Marchetto S, Le Bivic A, Ollendorff V, Jaulin-Bastard F, Saito H, Fournier E, Adelaide J, Margolis B, Birnbaum D (2000) ERBIN: a basolateral PDZ protein that interacts with the mammalian ERBB2/HER2 receptor. Nat Cell Biol 2:407-414.

Bryant PJ, Huwe A (2000) LAP proteins: what's up with epithelia? Nat Cell Biol 2:E141-143.

Dillon C, Creer A, Kerr K, Kumin A, Dickson C (2002) Basolateral targeting of ERBB2 is dependent on a novel bipartite juxtamembrane sorting signal but independent of the C-terminal ERBIN-binding domain. Mol Cell Biol 22:6553-6563.

Du Y, Weed SA, Xiong WC, Marshall TD, Parsons JT (1998) Identification of a novel cortactin SH3 domain-binding protein and its localization to growth cones of cultured neurons. Mol Cell Biol 18:5838-5851.

Huang YZ, Zang M, Xiong WC, Luo Z, Mei L (2003) Erbin suppresses the MAP kinase pathway. J Biol Chem 278:1108-1114.

Izawa I, Nishizawa M, Ohtakara K, Inagaki M (2002) Densin-180 interacts with delta-catenin/neural plakophilin-related armadillo repeat protein at synapses. J Biol Chem 277:5345-5350.

Jaulin-Bastard F, Arsanto JP, Le Bivic A, Navarro C, Vely F, Saito H, Marchetto S, Hatzfeld M, Santoni MJ, Birnbaum D, Borg JP (2002) Interaction between Erbin and a Catenin-related protein in epithelial cells. J Biol Chem 277:2869-2875.

Jones SB, Lanford GW, Chen YH, Moribito M, Kim K, Lu Q (2002) Glutamate-induced $\delta$-catenin redistribution and dissociation from postsynaptic receptor complexes. Neuroscience 115:1009-1021.

Kim K, Sirota A, Chen YH, Jones SB, Dudek R, Lanford GW, Thakore C, Lu Q (2002) Dendrite-like process formation and cytoskeletal remodeling regulated by delta-catenin expression. Exp Cell Res 275:171-184.

Laura RP, Witt AS, Held HA, Gerstner R, Deshayes K, Koehler MF, Kosik KS, Sidhu SS, Lasky LA (2002) The Erbin PDZ domain binds with high affinity and specificity to the carboxyl termini of delta-catenin and ARVCF. J Biol Chem 277:12906-12914.

Legouis R, Gansmuller A, Sookhareea S, Bosher JM, Baillie DL, Labouesse M (2000) LET-413 is a basolateral protein required for the assembly of adherens junctions in Caenorhabditis elegans. Nat Cell Biol 2:415-422.

Legouis R, Jaulin-Bastard F, Schott S, Navarro C, Borg JP, Labouesse M (2003) Basolateral targeting by leucine-rich repeat domains in epithelial cells. EMBO Rep 4:1096-1102.

Martinez MC, Ochiishi T, Majewski M, Kosik KS (2003) Dual regulation of neuronal morphogenesis by a delta-catenin-cortactin complex and Rho. J Cell Biol 162:99-111.

Naisbitt S, Kim E, Tu JC, Xiao B, Sala C, Valtschanoff J, Weinberg RJ, Worley PF, Sheng M (1999) Shank, a novel family of postsynaptic density proteins that binds to the NMDA receptor/PSD-95/GKAP complex and cortactin. Neuron 23:569-582.

Romorini S, Piccoli G, Jiang M, Grossano P, Tonna N, Passafaro M, Zhang M, Sala C (2004) A functional role of postsynaptic density-95-guanylate kinase-associated protein complex in regulating shank assembly and stability to synapses. J Neurosci 24:9391-9404.

Roth A, Kreienkamp HJ, Meyerhof W, Richter D (1997) Phosphorylation of four amino acid residues in the carboxyl terminus of the rat somatostatin receptor subtype 3 is crucial for its desensitization and internalization. J Biol Chem 272:23769-23774.

Saito H, Santoni MJ, Arsanto JP, Jaulin-Bastard F, Le Bivic A, Marchetto S, Audebert S, Isnardon D, Adelaide J, Birnbaum D, Borg JP (2001) Lano, a novel LAP protein directly connected to MAGUK proteins in epithelial cells. J Biol Chem 276:32051-32055.

Sala C, Piech V, Wilson NR, Passafaro M, Liu G, Sheng M (2001) Regulation of dendritic spine morphology and synaptic function by Shank and Homer. Neuron 31:115-130.

Sheng M, Kim E (2000) The Shank family of scaffold proteins. J Cell Sci 113:1851-1856

Soltau M, Richter D, Kreienkamp HJ (2002) The insulin receptor substrate IRSp53 links postsynaptic shank1 to the small G-protein cdc42. Mol Cell Neurosci 21:575-583.

Soltau M, Berhörster K, Richter D, Kreienkamp HJ (2004) Insulin receptor substrate of $53 \mathrm{kDa}$ links postsynaptic shank to PSD-95. J Neurochem 90:659-665.

Strack S, Robison AJ, Bass MA, Colbran RJ (2000) Association of calcium/ calmodulin-dependent kinase II with developmentally regulated splice variants of the postsynaptic density protein Densin-180. J Biol Chem 275:25061-25064.

Walikonis RS, Oguni A, Khorosheva EM, Jeng CJ, Asuncion FJ, Kennedy MB (2001) Densin-180 forms a ternary complex with the $\alpha$-subunit of $\mathrm{Ca}^{2+}$ / calmodulin-dependent protein kinase II and $\alpha$-actinin. J Neurosci 21:423-433.

Zitzer H, Hönck HH, Bächner D, Richter D, Kreienkamp HJ (1999) Somatostatin receptor interacting protein defines a novel family of multidomain proteins present in human and rodent brain. J Biol Chem 274:32997-33001. 